\title{
Oligomer Formation Pathways in Secondary Organic Aerosol from MS and MS/MS Measurements with High Mass Accuracy and Resolving Power
}

\author{
Wiley A. Hall IV, ${ }^{1}$ Murray V. Johnston ${ }^{2}$ \\ ${ }^{1}$ U.S. Department of Agriculture-Agricultural Research Service, San Joaquin Valley Agricultural Center, Parlier, CA, USA \\ ${ }^{2}$ Department of Chemistry and Biochemistry, University of Delaware, Newark, DE 19716, USA
}

\begin{abstract}
Secondary organic aerosol (SOA) is formed when organic molecules react with oxidants in the gas phase to form particulate matter. Recent measurements have shown that more than half of the mass of laboratory-generated SOA consists of high molecular weight oligomeric compounds. In this work, the formation mechanisms of oligomers produced in the laboratory by ozonolysis of a-pinene, an important SOA precursor in ambient air, are studied by MS and MS/MS measurements with high accuracy and resolving power to characterize monomer building blocks and the reactions that couple them together. The distribution of oligomers in an SOA sample is complex, typically yielding over 1000 elemental formulas that can be assigned from an electrospray ionization mass spectrum. Despite this complexity, MS/MS spectra can be found that give strong evidence for specific oligomer formation pathways that have been postulated but not confirmed. These include aldol and gem-diol reactions of carbonyls as well as peroxyhemiacetal formation from hydroperoxides. The strongest evidence for carbonyl reactions is in the formation of hydrated products. Less compelling evidence is found for dehydrated products and secondary ozonide formation. The number of times that a monomer building block is observed as a fragmentation product in the MS/MS spectra is shown to be independent of the monomer vapor pressure, suggesting that oligomer formation is not driven by equilibrium partitioning of a monomer between the gas and particle phases, but rather by reactive uptake where a monomer collides with the particle surface and rapidly forms an oligomer.
\end{abstract}

Key words: Secondary organic aerosol, High resolution mass spectrometry, ESI-FTICR-MS, Oligomerization, IRMPD

\section{Introduction}

Secondary organic aerosol (SOA) is produced by the $\checkmark$ reaction of volatile organic compounds (VOC) with an

Electronic supplementary material The online version of this article (doi:10.1007/s13361-012-0362-6) contains supplementary material, which is available to authorized users.

Correspondence to: Murray Johnston; e-mail: mvj@udel.edu atmospheric oxidant $\left(\mathrm{O}_{3}, \mathrm{NO}_{\mathrm{x}}\right.$, or $\left.\mathrm{OH}\right)$ to form particulate matter. Between $30 \%$ and $80 \%$ of the particulate matter in ambient air, depending on location and time of year, is carbonaceous [1], and the majority of this material is SOA $[1,2]$. For this reason, it is important to elucidate mechanisms of SOA formation. The initial step of VOC oxidation often produces semivolatile organic compounds (SVOC), a portion of which may partition from the gas phase to the particle phase. SVOC can react further to 
produce nonvolatile organic compounds (NVOC) that reside fully in the particle phase [3,4]. Recent measurements of laboratory generated SOA show that oligomers formed by the reaction of SVOC monomers to produce mostly dimer and trimer species constitute more than half of the NVOC $[5,6]$. Because of the large number of monomer building blocks and reactions that may couple them together, these oligomers exhibit great molecular complexity. For example, oligomers derived from the ozonolysis of $\alpha$-pinene encompass over 1000 unique elemental formulas in the 150-1000 Da range, all formed within a few seconds of reaction [7, 8].

Accurate mass analysis has played an important role in oligomer characterization beginning with a study of oligomers derived from $\alpha$-pinene ozonolysis [9]. Since then, many applications have been reported, and the field has been recently reviewed by Nizkorodov et al. [10]. Van Krevelen plots have been used to identify molecular compositional domains $[2,8]$ that give insight into oligomer formation reactions and building blocks. Kendrick mass defect plots have been used to aid in molecular formula assignments by identifying homologous ion series [10]. Some indirect evidence for specific oligomerization reactions has been gained through accurate mass measurement. For example, it has been observed that dimers tend to have elemental formulas with lower $\mathrm{O}: \mathrm{C}$ ratios than monomers, which could indicate the loss of water from condensation reactions between carbonyl groups [11]. Correlating measured oligomer elemental formulas with predicted formulas based on combinations of known monomers and intermediates has suggested that carboxylic acid groups [12], the stabilized Criegee intermediate [8], and hydroperoxide intermediates $[8,12]$ may be important monomer building blocks. Recently, accurate mass analysis has been extended to tandem mass spectrometry $\left(\mathrm{MS}^{\mathrm{n}}\right)$ experiments either by direct infusion $[9,13]$ or coupled with liquid chromatography [14] to more fully characterize specific oligomer products of interest.

In the work presented here, MS/MS product ion spectra with high mass accuracy and resolving power are obtained for a large number of oligomers found in SOA produced by $\alpha$-pinene ozonolysis. Monoterpenes in general and $\alpha$-pinene in particular are considered to be major precursors to SOA on a global basis $[1,15]$. These measurements are used to characterize monomer building blocks and provide compelling molecular evidence for a variety of oligomer formation reactions that until now have been only postulated.

\section{Experimental}

\section{Sample Preparation}

SOA was generated by mixing $\alpha$-pinene (a mixture of + and enantiomers, 98\% purity, Sigma-Aldrich no. 147524; St. Louis, MO, USA) vapor and ozone in a $500 \mathrm{~L}$ Tedlar bag. First, the flow from an ozone generator (model PZ5; Prozone, Huntsville, AL, USA) was directed into the bag
( $\sim \mathrm{min}$ of flow at $3 \mathrm{~L} / \mathrm{min}$ and $150-200 \mathrm{ppbv}$ ozone). The bag was then filled with clean, dry air (final relative humidity after addition of reactants was $\sim 5 \%$ ) to a volume of $500 \mathrm{~L}(36.4 \mathrm{~L} / \mathrm{min}$ for $13.75 \mathrm{~min})$, and the ozone concentration was measured with an ozone analyzer (model $49 \mathrm{C}$; Thermo Scientific, Waltham, MA, USA). $\alpha$-Pinene vapor was added, in excess, to the bag by redirecting the air flow into the bag through an impinger spiked with $20 \mu \mathrm{L}$ of $\alpha$-pinene liquid at a flow rate of $3.3 \mathrm{~L} / \mathrm{min}$ for $5 \mathrm{~min}$. The reaction was allowed to proceed for 45 min following the beginning of the $\alpha$-pinene addition. A scanning mobility particle sizer (model 3080/3025A SMPS; TSI, St. Paul, MN, USA) was used to measure the mass concentration and size distribution of SOA in the bag every 5 min during the reaction. At the end of the reaction time, the bag was evacuated with a vacuum pump (model 1HAB-25-M100X Gast; Benton Harbor, MI, USA) at a flow rate $\sim 26 \mathrm{~L} / \mathrm{min}$, with the aerosol collected on an inline filter $(47 \mathrm{~mm}$ Fiberfilm; Pall Life Sciences, Port Washington, NY, USA). A total of eight filter samples were prepared in this manner, and each was extracted along with a blank filter, with $8 \mathrm{~mL}$ of acetonitrile. A Savant speed concentrator (model SC110A; Thermo Scientific, Waltham, MA, USA) was used to take each sample to $0.5-1 \mathrm{~mL}$, and the samples were centrifuged to remove any solid debris such as pieces of filter. The SOA extracts were combined and adjusted to a final volume of $7 \mathrm{~mL}$ with ACN. The blank extracts were combined and adjusted in the same manner. Past experiments have shown that extraction solvent has little to no effect on the individual compounds extracted from the filters (or at least on the molecular formulas assigned to them) [6]. Additional experiments performed in this work show that exposing collected SOA to lab air for several hours has no effect on oligomer distribution or the average oxygen to carbon and hydrogen to carbon ratios of the formulas assigned to extracted compounds.

\section{Sample Analysis}

The SOA and blank samples were analyzed with a $7 \mathrm{~T}$ electrospray ionization Fourier transform ion cyclotron resonance (ESI-FTICR) mass spectrometer (model ApexQe; Bruker, Billerica, MA, USA) equipped with a carbon dioxide laser $(10.6 \mu \mathrm{m}, 25 \mathrm{~W})$ for infrared multiphoton dissociation (IRMPD). Two $3 \mathrm{~mL}$ aliquots were taken from each sample: one aliquot was spiked with $1 \mathrm{~mL} \mathrm{H}_{2} \mathrm{O}$ for positive ion analysis, and the other aliquot was spiked with $1 \mathrm{~mL} 4 \mu \mathrm{M} \mathrm{NH} \mathrm{N}_{4} \mathrm{OH}$ for negative ion analysis. A sample spiked with $1 \mathrm{~mL} 4 \mu \mathrm{M} \mathrm{NH} \mathrm{NH}_{4} \mathrm{OH}$ was analyzed in negative ion mode at $\sim 10 \mathrm{~min}, 1,3$, and $2 \mathrm{~h}$ after spiking with no significant changes in oligomer distribution, or in the molecular formulas assigned to the detected peaks. The same result was observed comparing positive mode analysis of samples in pure acetonitrile (ACN) and 75/25 ACN/ $\mathrm{H}_{2} \mathrm{O}$. The $\mathrm{m} / \mathrm{z}$ range analyzed was $97-1500$ from a $0.4719 \mathrm{~s}$ transient containing $1 \mathrm{M}$ data points. The source and ion 
accumulation times were 0.02 and $1.0 \mathrm{~s}$, respectively. ESI was performed with a sample flow rate of $150 \mu \mathrm{L} / \mathrm{h}$. IRMPD was performed with three laser shots at $50 \%$ power. Ten spectra $(m / z$ 97-1500) were acquired and combined for each analysis.

A $-5 \mathrm{~V}$ potential difference (positive mode) was applied between the ion funnel at the entrance to the instrument and the collision cell immediately downstream to minimize noncovalent cluster formation during sample introduction. When a cis-pinonic acid (98\%, SigmaAldrich no. 110108) standard solution was analyzed at $0 \mathrm{~V}$ collision voltage, a large peak was observed at $\mathrm{m} / \mathrm{z}$ 391 corresponding to the noncovalent dimer of pinonic acid $\left(\mathrm{C}_{20} \mathrm{H}_{32} \mathrm{O}_{6} \mathrm{Na}^{+}\right)$. When the collision voltage was increased slightly to $-5 \mathrm{~V}$, this peak disappeared. In contrast, when an ion with the same accurate $\mathrm{m} / \mathrm{z}$ was isolated from the SOA sample, increasing the collision voltage had little effect on the signal intensity, indicating that this ion is more likely to be a covalently bound dimer produced from the ozonolysis reaction. Similar effects were observed in negative ion mode $(+5 \mathrm{~V}$ potential difference) with the pinonic acid standard solution, and in both polarity modes with a pinic acid standard (from Sigma-Aldrich's rare chemical library, purity not given) solution.

\section{Identification of Precursors and Products}

For the MS/MS experiments, each odd $\mathrm{m} / \mathrm{z}$ precursor ion within the range of interest $(\mathrm{m} / \mathrm{z}$ 163-623 for positive mode, 139-599 for negative mode) was isolated by a quadrupole located between the ESI source and the ICR cell. If the intensity of the target ion(s) was over 1E5 after optimization of the isolation window (maximizing the target ion signal while minimizing the $\mathrm{M}-1$ and $\mathrm{M}+2$ peaks, which were generally under $10 \%$ relative intensity, but never greater than 20\%), two spectra were acquired: an "isolation" spectrum with the IRMPD laser off, and a "fragmentation" spectrum where the cell was irradiated with three $1 \mathrm{~s}$ laser shots at $50 \%$ power. Isolation and fragmentation peak lists were developed from the two types of spectra from the SOA sample. Also, background isolation and fragmentation peak lists were developed from analysis of the blank sample. The SOA and background peak lists were then compared. Peaks with matching $\mathrm{m} / \mathrm{z}$ (within $1.5 \mathrm{ppm}$ ) and a signal-to-noise ratio in the blank spectrum that was 10 times greater than the signal-to-noise ratio in the SOA spectrum were eliminated from the SOA peak lists. The signal-to-noise ratio criterion was chosen to remove the most prominent blank peaks whereas at the same time retaining low intensity peaks in the SOA sample that may not have had a significant background contribution. Removed peaks appearing in both the SOA and blank peak lists were flagged for possible consideration in detailed interpretation of product ion spectra.

SOA peak assignments were made by comparison with a list of the possible $\mathrm{CHO}$ elemental formulas (as $\mathrm{M}+\mathrm{H}^{+}$or $\mathrm{M}+\mathrm{Na}^{+}$ in positive ion mode, or $\mathrm{M}-\mathrm{H}^{-}$in negative mode). If a given $\mathrm{m} / \mathrm{z}$ (plus the mass of an electron for positive mode, minus the mass of an electron in negative mode), was within $5 \mathrm{ppm}$ (10 ppm for $\mathrm{m} / z<200$ ) of the $\mathrm{m} / z$ of a given elemental formula, the matching elemental formula was assigned to the peak being examined. The average mass accuracy was $\pm 2.39 \mathrm{ppm}$ for $\mathrm{m} /$ $z>200$, and \pm 3.19 for $m / z<200$. The isolation list was used to identify all possible precursor ions in the isolation spectra. For this work, a precursor ion was defined as any ion with an intensity of greater than $50 \%$ of the base peak, which was considered a high enough intensity to potentially contribute fragments during IRMPD. Isolation peaks eliminated by this criterion were flagged for possible consideration in the detailed interpretation of fragmentation spectra.

The next step was determining which ions in each individual fragmentation spectrum could reasonably be considered to be a product ion of the precursor ion(s) for that spectrum. A peak $\left(m / z=\mathrm{M}_{\mathrm{f}}\right)$ was considered to be a reasonable product ion from a given precursor $\left(m / z=\mathbf{M}_{\mathrm{p}}\right)$ if $M_{p}-M_{f} \geq 12$, and there were no increases in the number of any species of atom (e.g., the number of hydrogen atoms in the precursor ion $\geq$ the number of hydrogen atoms in the product ion). For spectra with more than one precursor ion at the nominal $\mathrm{m} / \mathrm{z}$ selected, a given ion in the fragmentation spectrum could potentially meet these criteria for multiple precursors. In these instances, the product ion was considered able to be formed from all of the relevant precursors. For each reasonable product ion, the elemental formula of the neutral loss from the precursor ion was determined.

The above process gave 69 nominal $\mathrm{m} / \mathrm{z}$ values that were isolated, corresponding to 100 precursor ion molecular formulas that had sufficient intensity to be interrogated by IRMPD, yielding 6040 product ion peaks and 8280 reasonable precursor-product combinations, all in positive ion mode. In negative ion mode, the bias toward ionization of monomers [5, 6] caused formation of a large amount of in-source clusters complicating interpretation of the spectra. For this reason, only positive ion mode data are reported here.

\section{Expected Dimers (Precursors)}

Supplemental Figures S1and S2 show the structures of 34 molecular species (stable monomers and intermediates) that have identified or postulated for SOA produced by $\alpha$-pinene ozonolysis $[1,16,17]$ plus $\alpha$-pinene. From this group of starting compounds, dimer products were postulated based on previously reported $[1,3,9,17,18]$ reactions between the oxygen-containing functional groups attached to the dimethyl-cyclobutane ring. These structures are shown in Supplemental Figure S3. Each of the potential dimers is given a three digit code: $\mathrm{C}_{1}-\mathrm{C}_{2}-\mathrm{R}$, where $\mathrm{C}_{1}$ and $\mathrm{C}_{2}$ refer to the compound number of the two reactants from Figures $\mathrm{S} 1$ and $\mathrm{S} 2$ that form the dimer and $\mathrm{R}$ refers to the type of reaction as summarized in Table 1. The goal of the " $R$ " designation is to distinguish products derived from at least one hydroperoxide reactant from those that cannot be derived from a hydroper- 
oxide reactant. For reactions $1-3$, the elemental formulas of the two reactants do not correspond to any known or postulated hydroperoxides. For type 1 reactions, the dimer mass $\left(\mathrm{M}_{\mathrm{D}}\right)$ is equal to the sum of the masses of the two monomers that form it $\left(\mathrm{M}_{1}\right.$ and $\left.\mathrm{M}_{2}\right)$. These reactions include (row and column from Figure $\mathrm{S} 3$ given in parenthesis) aldol addition (i.e., 2Biii), hemiacetal formation (1B), and the formation of a di( $\alpha$-hydroxy) ether (through a gem-diol intermediate) followed by loss of $\mathrm{H}_{2} \mathrm{O}$ (i.e., 2Aii). For type 2 reactions, the dimer mass also includes the loss of a water molecule (i.e., $\mathrm{M}_{\mathrm{D}}=\mathrm{M}_{1}+\mathrm{M}_{2}-\mathrm{M}_{\mathrm{H} 2 \mathrm{O}}$. These reactions include ester (1C) and anhydride formation (4C), and aldol addition followed by dehydration (i.e., 3Biv). For type 3 reactions, the dimer mass includes addition of a water molecule (i.e., $\mathrm{M}_{\mathrm{D}}=\mathrm{M}_{1}+\mathrm{M}_{2}+\mathrm{M}_{\mathrm{H} 2 \mathrm{O}}$. The main type 3 reaction is di( $\alpha$-hydroxy) ether formation through a gemdiol intermediate (i.e., 2Bii). Reaction types 4, 5, and 6, all involve reactions where at least one of the reactant elemental formulas corresponds exclusively to a hydroperoxide. For a type 4 reaction, $M_{D}=M_{1}+M_{2}$. For a type 5 reaction, $M_{D}=$ $\mathrm{M}_{1}+\mathrm{M}_{2}-\mathrm{M}_{\mathrm{H} 2 \mathrm{O}}$. For a type 6 reaction, $\mathrm{M}_{\mathrm{D}}=\mathrm{M}_{1}+\mathrm{M}_{2}+$ $\mathrm{M}_{\mathrm{H} 2 \mathrm{O}}$. (Note that while reaction types 5 and 6 occur where one of the reactants has an $\mathrm{ROOH}$ group, the postulated reaction takes place between functional groups other than the ROOH on the molecules). Reaction types 7, 8, and 9, $\left(\mathrm{M}_{\mathrm{D}}=\mathrm{M}_{1}+\mathrm{M}_{2}, \mathrm{M}_{\mathrm{D}}=\mathrm{M}_{1}+\mathrm{M}_{2}-\mathrm{M}_{\mathrm{H} 2 \mathrm{O}}\right.$ and $\mathrm{M}_{\mathrm{D}}=\mathrm{M}_{1}+\mathrm{M}_{2}+$ $\mathrm{M}_{\mathrm{H} 2 \mathrm{O}}$, respectively) involve reactions where at least one reactant has an elemental formula that can correspond either to a hydroperoxide and/or stable Criegee intermediate or a non-hydroperoxide reactant-for example $\mathrm{m} / \mathrm{z}$ 184.109945 corresponds to both of the stablized Criegee intermediates and also to pinonic acid and three other non-hydroperoxide monomers. Finally, reaction type 10 refers to the reaction between two stabilized Criegee intermediates (SCIs) to form a ROOR type peroxide (5D) with the loss of $\mathrm{O}_{2}\left(\mathrm{M}_{\mathrm{D}}=\mathrm{M}_{1}+\mathrm{M}_{2}-\mathrm{M}_{\mathrm{O} 2}\right)$. In all, there were 506 possible dimer codes.

While the dimer codes may seem complex, they provide a convenient way to search precursors and their product mass

Table 1. Dimer Reaction Classifications

\begin{tabular}{|c|c|c|}
\hline $\begin{array}{l}\text { Reaction } \\
\text { type }\end{array}$ & Description & $\Delta m / z$ \\
\hline $\begin{array}{l}1 \\
2 \\
3\end{array}$ & $\begin{array}{l}\text { Reactions involving no } \\
\text { hydroperoxides or } \\
\text { Criegee intermediates }\end{array}$ & $\begin{array}{l}\mathrm{M}_{\mathrm{D}}=\mathrm{M}_{1}+\mathrm{M}_{2} \\
\mathrm{M}_{\mathrm{D}}=\mathrm{M}_{1}+\mathrm{M}_{2}-\mathrm{M}_{\mathrm{H} 2 \mathrm{O}} \\
\mathrm{M}_{\mathrm{D}}=\mathrm{M}_{1}+\mathrm{M}_{2}+\mathrm{M}_{\mathrm{H} 2 \mathrm{O}}\end{array}$ \\
\hline $\begin{array}{l}4 \\
5 \\
6\end{array}$ & $\begin{array}{l}\text { Reactions involving at least } \\
\text { one hydroperoxide }\end{array}$ & $\begin{array}{l}\mathrm{M}_{\mathrm{D}}=\mathrm{M}_{1}+\mathrm{M}_{2} \\
\mathrm{M}_{\mathrm{D}}=\mathrm{M}_{1}+\mathrm{M}_{2}-\mathrm{M}_{\mathrm{H} 2 \mathrm{O}} \\
\mathrm{M}_{\mathrm{D}}=\mathrm{M}_{1}+\mathrm{M}_{2}+\mathrm{M}_{\mathrm{H} 2 \mathrm{O}}\end{array}$ \\
\hline $\begin{array}{l}7 \\
8 \\
9\end{array}$ & $\begin{array}{l}\text { Reactions that can involve } \\
\text { hydroperoxides and/or } \\
\text { Criegee intermediates } \\
\text { with other compounds }\end{array}$ & $\begin{array}{l}M_{D}=M_{1}+M_{2} \\
M_{D}=M_{1}+M_{2}-M_{H 2 O} \\
M_{D}=M_{1}+M_{2}+M_{H 2 O}\end{array}$ \\
\hline 10 & $\begin{array}{l}\text { Reactions between two } \\
\text { Criegee intermediates }\end{array}$ & $\mathrm{M}_{\mathrm{D}}=\mathrm{M}_{1}+\mathrm{M}_{2}-\mathrm{M}_{\mathrm{O} 2}$ \\
\hline
\end{tabular}

spectra for evidence of specific types of reactions (e.g., aldol or gem-diol reactions) and specific types of reactants (e.g., hydroperoxides). They also provide a convenient way to specify dimer formation mechanisms and reactants. This study does not explicitly consider dimers formed by reaction of a monomer with a small molecule such as formaldehyde. Products of this type generally have much smaller molecular masses that the precursors discussed here.

\section{Results and Discussion}

\section{General Characteristics of Oligomer Fragmentation}

The complete MS/MS dataset is illustrated in Figure 1a as a plot of precursor formula weight (FW) versus product $\mathrm{FW}$. FW rather than $m / z$ is plotted since some ions are sodiated and while others are protonated. Neutral losses are indicated by diagonal lines. It is convenient to interpret this plot with respect to neutral losses rather than product FW because (1) several small molecule losses either do not efficiently retain charge or are below the low $\mathrm{m} / \mathrm{z}$ cutoff for the analysis, and (2) it is conceptually more difficult to visualize dimer versus trimer fragmentation based on product FW. For these reasons, fragmentation products are summarized in Figure $1 \mathrm{~b}$ as the neutral loss FW versus the number of times it is observed in the dataset. The plot in Figure 1b clearly shows three types of fragments: those arising from a small molecule loss from the precursor ion, those arising from loss of a monomer building block, and (for trimers) those arising from loss of a dimer. The monomer and dimer loss regions are characterized by clusters of peaks separated by 14 or 16 mass units. The most common small fragment neutral losses include $\mathrm{H}_{2} \mathrm{O}$ (18.01057), $\mathrm{CH}_{2} \mathrm{O}$ (30.01057), $\mathrm{CH}_{2} \mathrm{O}_{2}$ (46.00548), and $\mathrm{C}_{2} \mathrm{H}_{4} \mathrm{O}_{2}$ (60.02113). In the monomer region, the most often observed neutral losses are $\mathrm{C}_{9} \mathrm{H}_{14} \mathrm{O}_{3}$ (170.09430), $\mathrm{C}_{10} \mathrm{H}_{16} \mathrm{O}_{3}$ (184.10995), $\left(\mathrm{C}_{10} \mathrm{H}_{16} \mathrm{O}_{4}\right.$ (200.10486), $\mathrm{C}_{10} \mathrm{H}_{16} \mathrm{O}_{2}$ (168.11503), $\mathrm{C}_{9} \mathrm{H}_{14} \mathrm{O}_{4}$ (186.08921), $\mathrm{C}_{8} \mathrm{H}_{12} \mathrm{O}_{4}(172.10995)$, and $\mathrm{C}_{10} \mathrm{H}_{16} \mathrm{O}_{5}(216.099775)$. Each of those formulas corresponds to a known monomer or intermediate in Figures $\mathrm{S} 1$ or $\mathrm{S} 2$ (e.g., $\mathrm{C}_{9} \mathrm{H}_{14} \mathrm{O}_{3}$ can be pinalic or norpinonic acid, $\mathrm{C}_{10} \mathrm{H}_{16} \mathrm{O}_{2}$ is pinonaldehyde, and $\mathrm{C}_{10} \mathrm{H}_{16} \mathrm{O}_{5}$ corresponds to hydroperoxide intermediate no. 6). Several of the monomer neutral losses with the greatest number of observations also often represent the most intense fragment ion in the product ion spectrum, especially those corresponding to losses of $\mathrm{C}_{9} \mathrm{H}_{14} \mathrm{O}_{3}, \mathrm{C}_{10} \mathrm{H}_{16} \mathrm{O}_{3}$, and $\mathrm{C}_{10} \mathrm{H}_{16} \mathrm{O}_{5}$.

\section{Monomer Building Blocks}

The number of observations in Figure $1 \mathrm{~b}$ for each of the 34 monomers shown in Figures S1 and S2 are replotted in Figure 2 versus estimated vapor pressure of the monomer calculated using the program EPI Suite [19]. Constructing this plot is complicated by the fact that several elemental formulas 
(a)

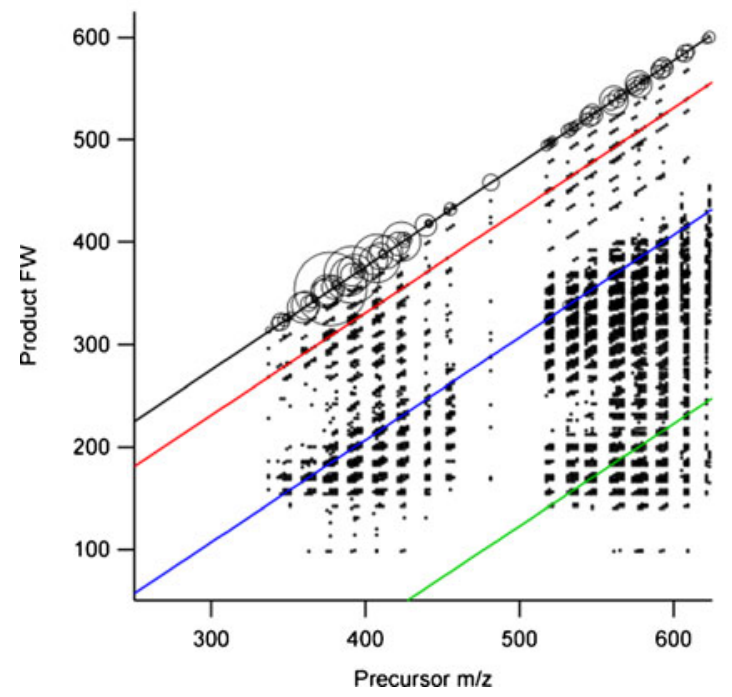

(b)

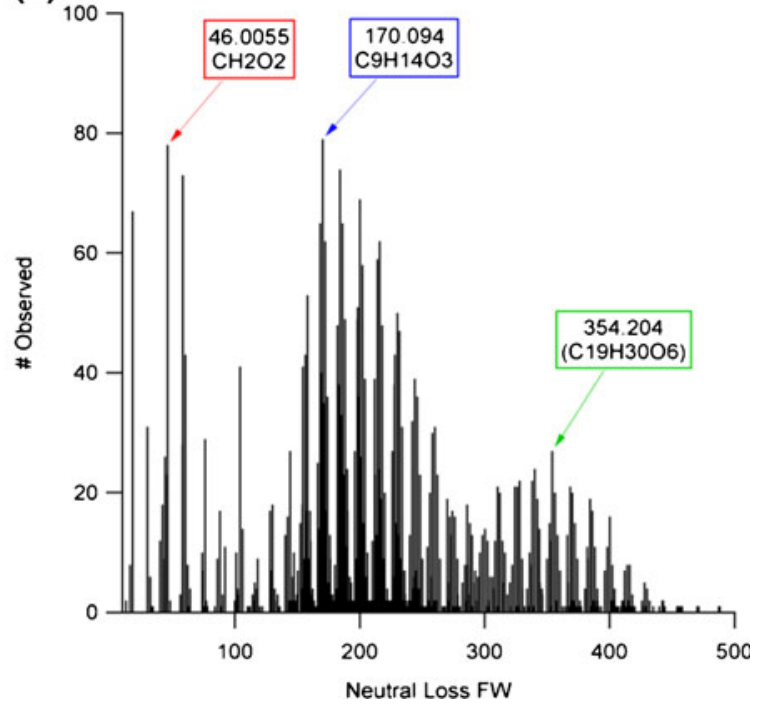

Figure 1. (a) Product ion assigned formula weight (FW) against its precursor FW (marker size proportional to intensity) for all fragmentation spectra. Diagonal lines indicate products with the same neutral loss. FW is the desodiated or deprotonated mass for each elemental formula assignment. (b) Neutral loss FW versus number of observations (number of fragmentation spectra showing the neutral loss)

correspond to isomeric monomers. For some observations, one or more monomers were excluded from consideration because they could not combine with another monomer by one of the reactions in Figure S3 to give the precursor FW. In cases where the difference in vapor pressure between the isomers was less than $50 \%$, the vapor pressures were averaged and the total number of observations was plotted versus average vapor pressure. Nonetheless, even with these simplifications, situations arose where more than one compound could explain a given monomer elemental formula. Because of this ambiguity, the data in Figure 2 were plotted in several ways to explore the relationship between monomer vapor pressure and number of observations.

The version of the plot shown in Figure 2a includes a data point for each of the 34 compounds, except that isomers with vapor pressures within $50 \%$ of each other are represented by a single data point at the average vapor pressure. In other words, if a given elemental formula corresponded to two compounds on the list having vapor pressures differing by more than $50 \%$, the total number of observations of that species in the fragmentation spectra was plotted twice- once at the vapor pressure of each compound. The ensuing plot in Figure 2a shows no discernable relationship between monomer vapor pressure and the number of times the monomer is observed in an oligomeric product. To test whether or not the multiple plotting of data for isomeric compounds masked a systematic relationship between vapor pressure and number of observations, the data were replotted in a manner that would yield the greatest bias toward a relationship. The version of the plot in Figure $2 b$ assumes that monomer vapor pressure is inversely related to the number of observations. In this plot, the elemental formulas with the highest number of observations were assigned the lowest vapor pressure among the isomeric compounds, while the elemental formulas with the lowest number of observations were assigned the highest vapor pressure among the isomeric compounds. The plot in Figure $2 \mathrm{~b}$ shows that even when the data are biased as much as possible toward an inverse relationship, no relationship is observed. Conversely, the version in Figure $2 \mathrm{c}$ makes the opposite assumption that vapor pressure is directly proportional to the number of observations. Here, the elemental formulas with the highest number of observations were assigned the highest vapor pressure among the isomers, whereas elemental formulas with the lowest number of observations were assigned the lowest vapor pressure among the isomers. Again, even when the data are biased as much as possible toward a relationship, none is observed. Taken together, the three plots in Figure 2 (manipulated points in red) argue strongly against a systematic relationship between vapor pressure and the ability of a monomer to form oligomers.

\section{Oligomerization Reactions}

In principle, comparison of the fragmentation spectrum of a given oligomeric precursor to the spectrum that would be expected for an expected dimer product can be used to provide compelling evidence for specific oligomerization reactions. However, there are many complications. To understand the complexity, consider the peak at $\mathrm{m} / \mathrm{z}$ 375.178 ; the formula assigned to it, $\mathrm{C}_{20} \mathrm{H}_{32} \mathrm{O}_{5} \mathrm{Na}^{+}$, matches six expected dimer products, each of which represents several possible molecular structures. The expected dimer 7-9-1, for instance, is one possible match; monomer no. 7 represents three isomeric compounds (pinalic-4-acid, norpinonic acid, and norpinalic acid), monomer no. 9 represents two isomers (4 or 9-oxopinonaldehyde), and this leads to six 

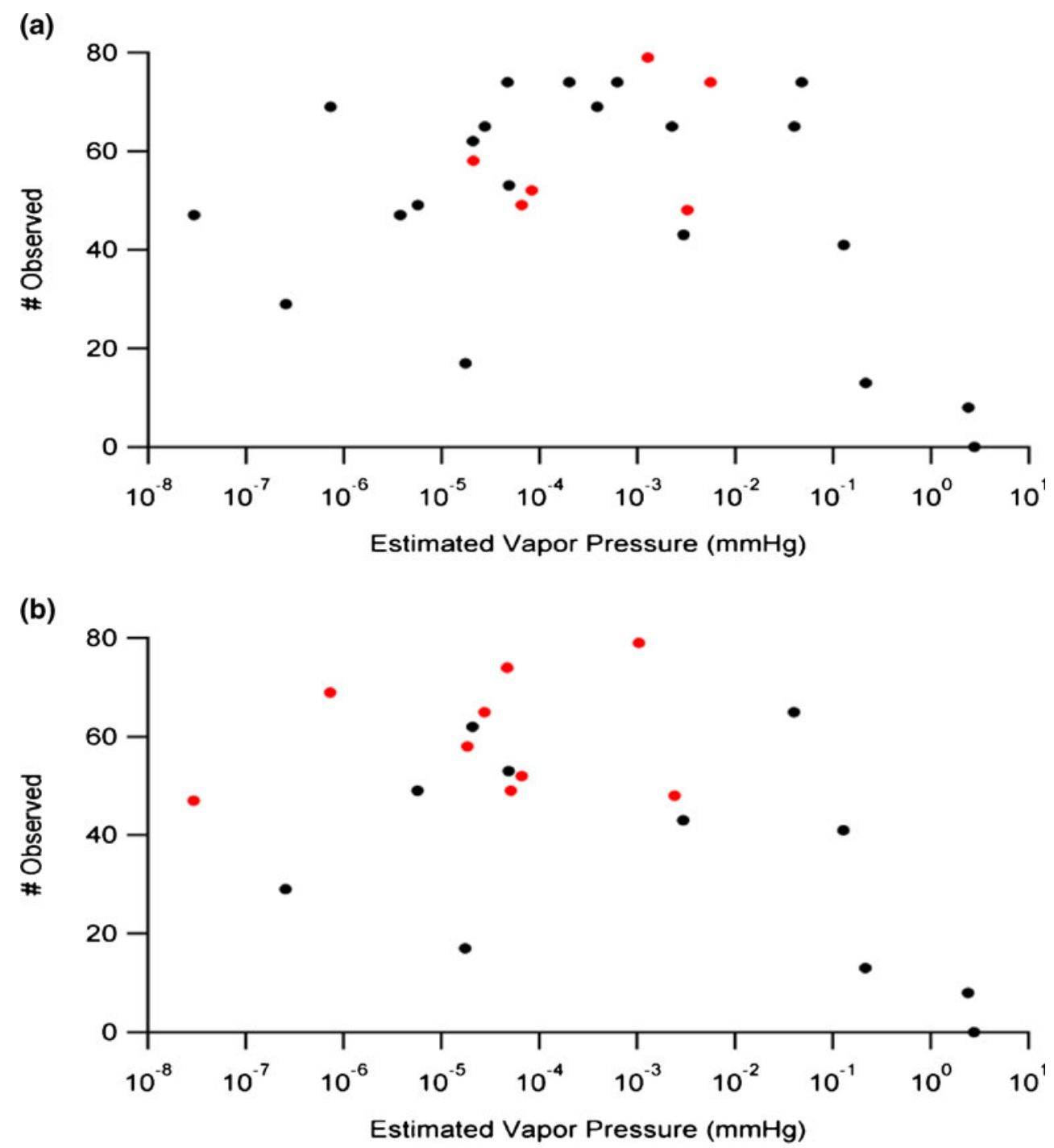

(c)

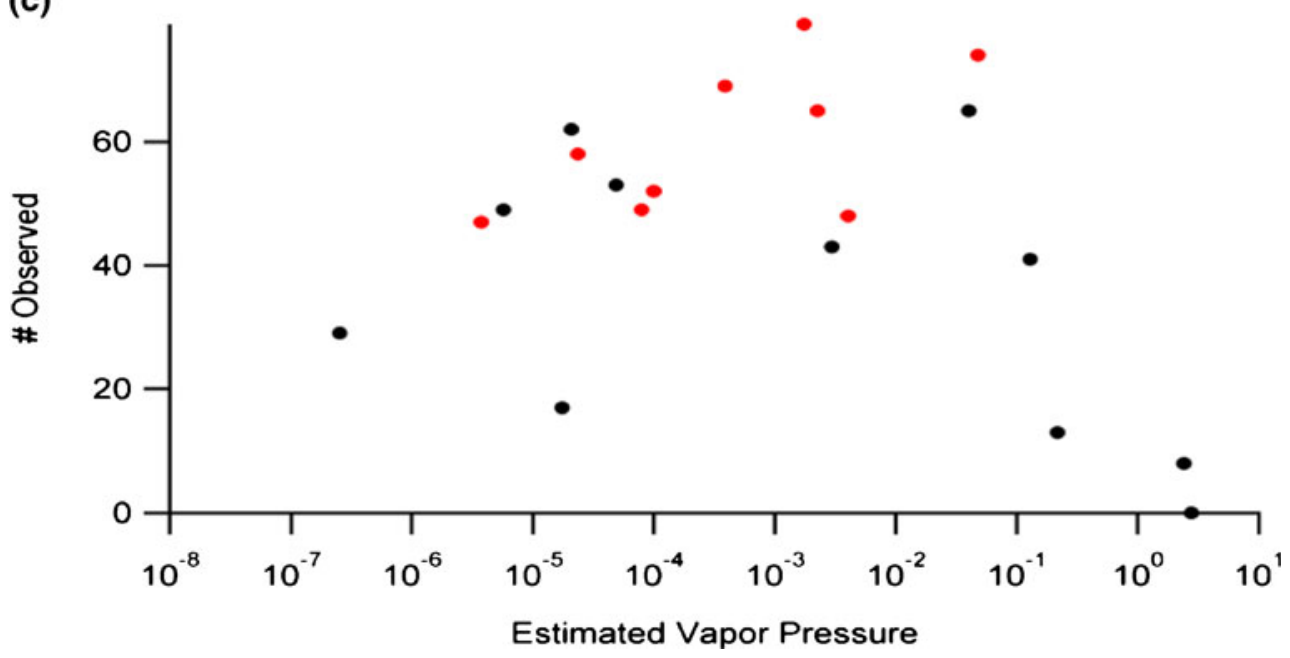

Figure 2. The number of observations that a monomer (as given by its elemental formula) is observed in the fragmentation spectra versus estimated vapor pressure of the monomer. In (a), all isomers for a given elemental formula are plotted. In (b), isomers are selected to bias the plot toward an inverse relationship between number of observations and vapor pressure (see text). In (c), isomers are selected to bias the plot toward a direct relationship between number of observations and vapor pressure. Red markers in (b) and (c) indicate the isomer data points that were selected to bias the plots 
unique permutations of monomers 7 and 9 (4-oxopinonaldehyde + norpinonic acid, 4-oxopinonaldehyde + pinalic-4-acid, etc.). Furthermore, for a given permutation, there can be several different dimer structures. If we know that Compound 7 is norpinonic acid and that Compound 9 is 9oxopinonaldehyde for a type- 1 reaction (where $\mathrm{M}_{\mathrm{D}}=\mathrm{M}_{1}+$ $\mathrm{M}_{2}$ ), the ketone group on norpinonic acid can form an aldol with either the ketone or an aldehyde on 9-oxopinonaldehyde (two different structures). Other type 1 reactions also include forming a dehydrated di( $\alpha$-hydroxy) ether between the same groups (two more different structures). Overall, the expected dimer 7-9-1 can be any of 18(!) different structures and it is just one out of six expected product codes that have to be considered to identify $\mathrm{m} / \mathrm{z} 375.214$. There is additional complexity when you consider that a given isolation $\mathrm{m} / \mathrm{z}$ can include more than one precursor ion, and each precursor ion can represent more than one isomeric structure. Strong evidence for the precursor identity and, therefore, the chemical reaction that formed it, is not possible for every (or indeed most) of the fragmentation spectra. Nonetheless, some spectra do provide compelling evidence for specific types of reactions and these are discussed below.

\section{Peroxyhemiacetal Formation ( $\mathrm{m} / \mathrm{z}$ 457.204)}

Figure 3 shows the proposed structure and fragmentation spectrum for the precursor at $\mathrm{m} / \mathrm{z} 457.204$ having an assigned formula $\mathrm{C}_{20} \mathrm{H}_{34} \mathrm{O}_{10} \mathrm{Na}^{+}$with mass accuracy of $2.42 \mathrm{ppm}$. The structure in Figure $3 \mathrm{a}$ is the peroxyhemiacetal dimer that would form from the reaction of hydroperoxide intermediates 4 and 7 (reaction $2 \mathrm{E}$ in Figure S3). The diagnostic peaks in the product ion spectrum (Figure 3b) are the series $\mathrm{C}_{10} \mathrm{H}_{16} \mathrm{O}_{4} \mathrm{Na}^{+}$, $\mathrm{C}_{10} \mathrm{H}_{16} \mathrm{O}_{5} \mathrm{Na}^{+}$, and $\mathrm{C}_{10} \mathrm{H}_{16} \mathrm{O}_{6} \mathrm{Na}^{+}$, which suggest a peroxy-type linking group as shown in the structure. The peak series $\mathrm{C}_{10} \mathrm{H}_{18} \mathrm{O}_{4-6} \mathrm{Na}^{+}$is also prominent in the spectrum and corresponds to product ions that would be formed by cleaving at the same points along the peroxy link, but with the positive charge remaining on the opposite side of the molecule. There are two other possible dimer matches for the formula $\mathrm{C}_{20} \mathrm{H}_{34} \mathrm{O}_{10}$, both of which are di( $\alpha$-hydroxy) ethers formed from the reaction of hydroperoxide intermediate no. 2 and either 4 or 9-oxopinonaldehyde, and diaterpenylic acid with one of the Compound 10 isomers. Neither of these dimer products can explain the $\mathrm{C}_{10} \mathrm{H}_{16} \mathrm{O}_{4-6} \mathrm{Na}^{+}$peak series. There are some prominent ions in the spectrum that cannot be explained by the assignment of $\mathrm{m} / \mathrm{z} 457.204$ to dimer code. One additional precursor ion $(\mathrm{m} / \mathrm{z}$ 457.349, $\mathrm{C}_{24} \mathrm{H}_{50} \mathrm{O}_{6} \mathrm{Na}^{+}, 2.42 \mathrm{ppm}$ ), which did not match any expected dimers at this isolation $\mathrm{m} / \mathrm{z}$, was observed, and the two peaks highlighted in purple are reasonable fragments for it. However, given the proposed structures, it is unlikely that the $\mathrm{C}_{10} \mathrm{H}_{16} \mathrm{O}_{4-6} \mathrm{Na}^{+}$series could come from it, especially $\mathrm{C}_{10} \mathrm{H}_{16} \mathrm{O}_{6} \mathrm{Na}^{+}$, which would require the loss of all oxygen atoms, but less than half of the carbon atoms. The ions highlighted in green have molecular formulas that are inconsistent with either of the above precursor ions. These ions likely arise from background that was not removed in the data analysis procedure. Taken together, the product ions in this spectrum provide strong evidence for the presence of a peroxyhemiacetal formed by the reaction of a hydroperoxide monomer.

\section{Peroxyhemiacetal and/or Acylhydroperoxide Formation ( $/ \mathrm{z}$ 379.172)}

The precursor at $\mathrm{m} / \mathrm{z} 379.172$ (only precursor ion at this isolation $\mathrm{m} / z$ ), identified as $\mathrm{C}_{18} \mathrm{H}_{28} \mathrm{O}_{7} \mathrm{Na}^{+}$with mass accuracy of $2.57 \mathrm{ppm}$, corresponds to two structural isomers: one a peroxyhemiacetal (reaction 2E in Figure S3) formed from the reaction of pinalic-4-acid and hydroperoxide intermediate no.1 (dimer 7-11-7, Figure 4a), the other an acylhydroperoxide (reaction 4D on Figure S3) formed from the reaction of norpinic acid and a Criegee intermediate (dimer 10-8-7, Figure 4b). The two most intense product ions in the spectrum are the sodiated ions of Compounds 7 (FW= 170.094) and $10(\mathrm{FW}=184.110)$, but these two cannot react with each other to form a product at the precursor $\mathrm{FW}$. Compound 7 has to react with Compound 11 (FW= 186.089), whereas Compound 10 has to react with Compound $8(\mathrm{FW}=172.074)$. For $10-8-7$, the only functional groups available for reaction in the Compound 8 isomers are carboxylic acids, and the only $\mathrm{M}_{\mathrm{D}}=\mathrm{M}_{1}+\mathrm{M}_{2}$ type reaction (types 1, 4, or 7 in Table 1) that acid groups participate in is the reaction with an SCI to form an acylhydroperoxide. The most likely Compound 8 monomer is norpinic acid, which is able to lose $\mathrm{CH}_{2} \mathrm{O}_{2}$, and the mostly likely Compound 10 monomer is SCI 2, which could give the loss of $\mathrm{C}_{2} \mathrm{H}_{2} \mathrm{O}$. The 10-8-7 dimer uniquely explains several peaks in the spectrum including $\mathrm{C}_{8} \mathrm{H}_{12} \mathrm{O}_{4} \mathrm{Na}^{+}$(Compound 8), $\mathrm{C}_{10} \mathrm{H}_{16} \mathrm{O}_{3} \mathrm{Na}^{+}$(Compound 10), $\mathrm{C}_{8} \mathrm{H}_{12} \mathrm{O}_{3} \mathrm{Na}^{+}, \mathrm{C}_{10} \mathrm{H}_{16} \mathrm{O}_{4} \mathrm{Na}$ ${ }^{+}$, and $\mathrm{C}_{11} \mathrm{H}_{16} \mathrm{O}_{5} \mathrm{Na}^{+}$. For dimer code 7-11-7, the peroxyhemiacetal shown in Figure 4a from the reaction of hydroperoxide intermediate 1 and norpinalic acid is the only combination of the Compounds 7 and 11 isomers that uniquely explains the fragment series $\mathrm{C}_{9} \mathrm{H}_{14} \mathrm{O}_{3-5} \mathrm{Na}^{+}$and the loss of $\mathrm{C}_{2} \mathrm{H}_{4} \mathrm{O}_{2}$. Both dimer codes (10-8-7 and 7-11-7) are consistent with the remaining small molecule losses. This spectrum provides additional evidence of peroxyhemiacetal formation and new evidence for acylhydroperoxide formation, in this case from a carboxylic acid and the stablized Criegee intermediate.

\section{Aldol Reaction $(\mathrm{m} / \mathrm{z}$ 375.214)}

The presence of oligomers formed by aldol condensation has been inferred by the decrease in $\mathrm{O}: \mathrm{C}$ ratios comparing monomers to oligomers [11] (indicative of the loss of $\mathrm{H}_{2} \mathrm{O}$ ), and by the observation of high resolution molecular ions $[9$, $11]$ as well as low resolution fragment ions that correspond 
(a)

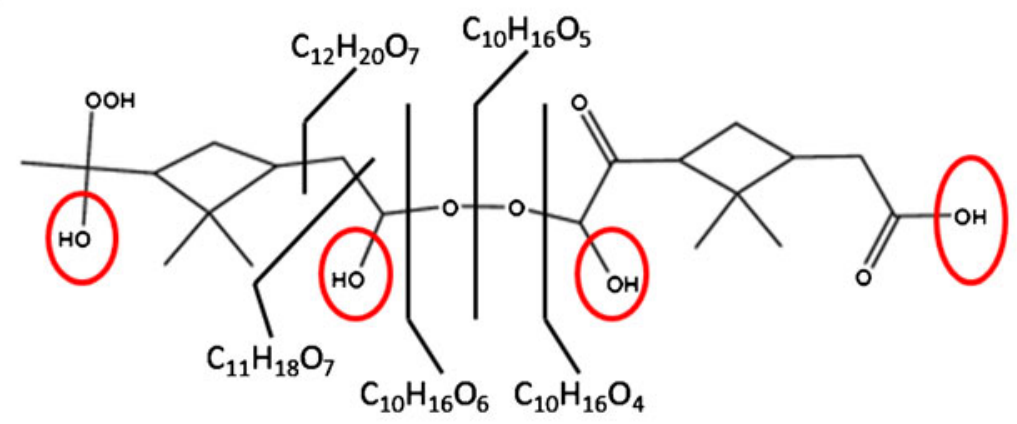

(b)

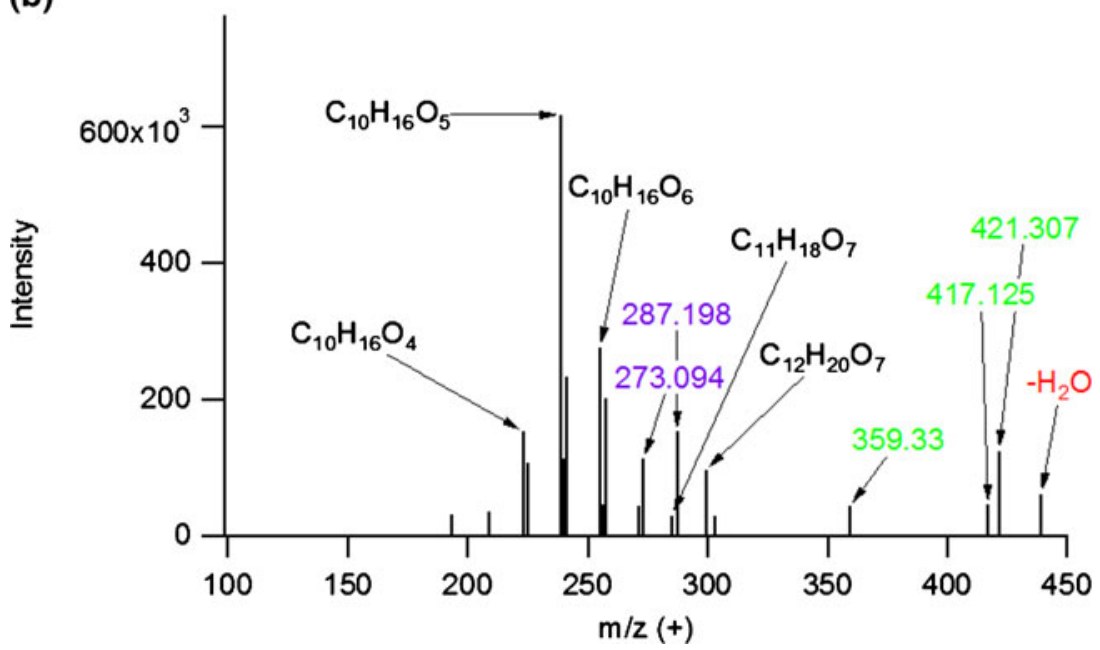

Figure 3. Evidence for peroxyhemiacetal formation from the reaction of a hydroperoxide. (a) Proposed structure for $\mathrm{m} / \mathrm{z}$ 457.204; (b) fragmentation spectrum for isolation of $\mathrm{m} / \mathrm{z} 457$, purple labeled peaks are most likely fragments from $\mathrm{m} / \mathrm{z} 457.349$ (another possible precursor at that nominal mass), green labeled peaks are not reasonable losses from either precursor ion

to aldol products [9]. The aldol condensation of carbonyl containing monomers has long been reported as an acidcatalyzed oligomerization reaction taking place in the particle phase [1, 20]. Here, evidence is shown for aldol condensation in non-acid-catalyzed conditions from the reaction of pinonaldehyde, which is too volatile to be found in the particle phase. The precursor at $\mathrm{m} / \mathrm{z} 375.214$ (only precursor at this isolation $m / z$ ) was identified as $\mathrm{C}_{20} \mathrm{H}_{32} \mathrm{O}_{5} \mathrm{Na}$ + with mass accuracy $2.51 \mathrm{ppm}$, and has a fragmentation spectrum consistent with the reaction of pinonaldehyde and pinonic acid to form an aldol (Figure 5, and reaction 3Biii in Figure S3). The most intense peaks in the spectrum have accurate masses consistent with these monomers. Pinonaldehyde is the only reported monomer with its MW, and the neutral loss of $\mathrm{CH}_{2} \mathrm{O}$ indicates that the ketone end of the compound is able to react. While the MW of pinonic acid also corresponds to five other isomeric compounds (Figure S1), pinonic acid is the only one with a carboxylic acid end group able to give the neutral loss of $\mathrm{CH}_{2} \mathrm{O}_{2}$. The expected dimer is shown in Figure 5a, and it uniquely explains the $\mathrm{C}_{10} \mathrm{H}_{16} \mathrm{O}_{2}$ and $\mathrm{C}_{10} \mathrm{H}_{16} \mathrm{O}_{3}$ sodiated fragments and $\mathrm{CH}_{2} \mathrm{O}_{2}$ neutral loss. The only other expected dimer that would have a formula of $\mathrm{C}_{20} \mathrm{H}_{32} \mathrm{O}_{5}$ is a dehydrated aldol formed between pinonaldehyde and hydroperoxide interme- diate, which is shown in Figure 5b. This dimer cannot explain the major monomer-type fragments in the spectrum nor are the expected monomer-type fragments from it observed. However, the presence of the dehydrated aldol is suggested by the presence of the $\mathrm{CH}_{2} \mathrm{O}_{3}$ neutral loss. Both dimer products provide compelling evidence for oligomer formation by an aldol reaction.

\section{Di( $\alpha$-hydroxy) Ether and Peroxyhemiacetal Formation (Nominal m/z 381)}

Two precursor ions are observed at the isolation $\mathrm{m} / \mathrm{z} 381 \mathrm{~m} /$ $z 381.188\left(\mathrm{C}_{18} \mathrm{H}_{30} \mathrm{O}_{7} \mathrm{Na}^{+}\right.$, with $2.68 \mathrm{ppm}$ mass accuracy), which corresponds to a di( $\alpha$-hydroxy) ether formed through a gem-diol intermediate by the reaction (2Bi in Figure S3) of 2,2-dimethyl-3-formyl-cyclobutyl-methanoic acid (Compound 5) and pinonic acid (Compound 10), and $\mathrm{m} / \mathrm{z}$ $381.152\left(\mathrm{C}_{17} \mathrm{H}_{26} \mathrm{O}_{8} \mathrm{Na}^{+}\right.$, with 2.46 ppm mass accuracy), which corresponds to a peroxyhemiacetal formed from the reaction ( $2 \mathrm{E}$ in Figure $\mathrm{S} 3$ ) of Compound 5 and hydroperoxide intermediate 3 , shown in Figure $6 a$ and b, respectively. Both proposed structures have $\mathrm{CH}_{2} \mathrm{COOH}$ and $\mathrm{COOH}$ functional groups that match the neutral losses observed, and, between them, the two structures shown can account for 
(a)

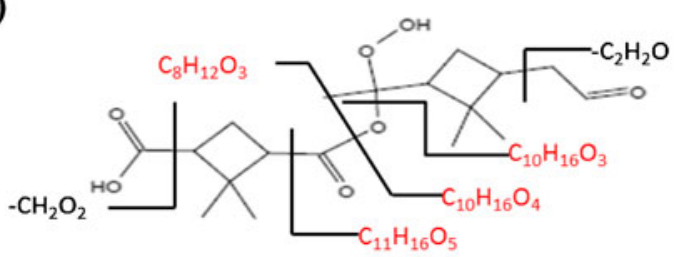

(b)

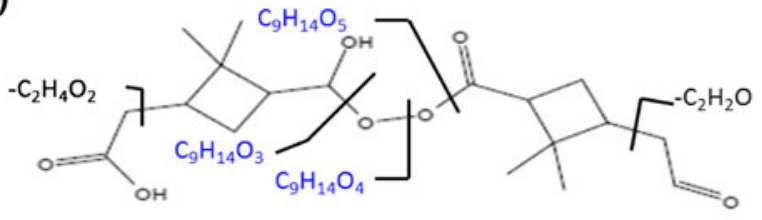

(c)

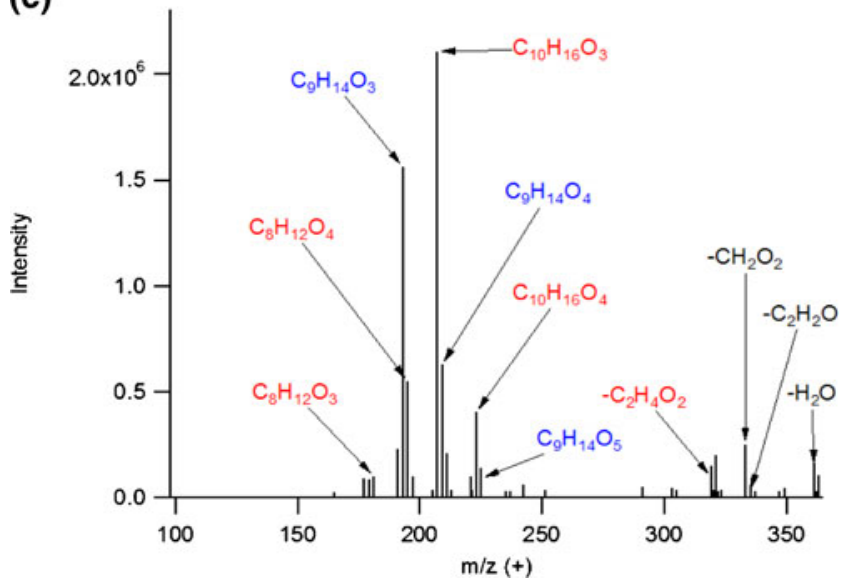

Figure 4. Evidence for peroxyhemiacetal and/or acylhydroperoxide formation. (a) and (b) The proposed structures for $\mathrm{m} / \mathrm{z}$ 379.172. (c) Fragmentation spectrum for isolation of $\mathrm{m} / \mathrm{z}$ 379 , peaks corresponding to the peroxyhemiacetal are labeled red, peaks corresponding to acylhydroperoxide are blue, and peaks that could be from either are black

all of the major peaks in the fragmentation spectrum as summarized in Figure 6c. There is additional circumstantial evidence for the di( $\alpha$-hydroxy) ether in the unusually large intensity of the product ion representing the neutral loss of water (relative intensity $=4.6 \%$, compared with an average relative intensity of $1.5 \% \pm 1.3 \%$ for this loss in other product ion spectra). It has been speculated that di( $\alpha$-hydroxy) ethertype oligomers may undergo dehydration [9]. For the entire MSMS dataset, each of the fragmentation spectra having the neutral loss of water with a relative intensity greater than one standard deviation above the average has at least one $\operatorname{di}(\alpha-$ hydroxy) ether dimer as a possible match. There is some evidence that other possible expected dimers for $\mathrm{C}_{18} \mathrm{H}_{30} \mathrm{O}_{7} \mathrm{Na}^{+}$and $\mathrm{C}_{17} \mathrm{H}_{26} \mathrm{O}_{8} \mathrm{Na}^{+}$are also present, for example two possible dimers formed from the reaction of one of the Compound 7 monomers could account for $\mathrm{C}_{9} \mathrm{H}_{16} \mathrm{O}_{3} \mathrm{Na}^{+}$and $\mathrm{C}_{9} \mathrm{H}_{16} \mathrm{O}_{4} \mathrm{Na}^{+}$, which are the two peaks observed in the spectrum that are not easily explained by the structures in Figure $6 \mathrm{a}$ and $\mathrm{b}$. However, these are minor peaks, and the dimers cannot explain the major peaks in the product ion spectrum. The two dimers shown in Figure 6 (a)
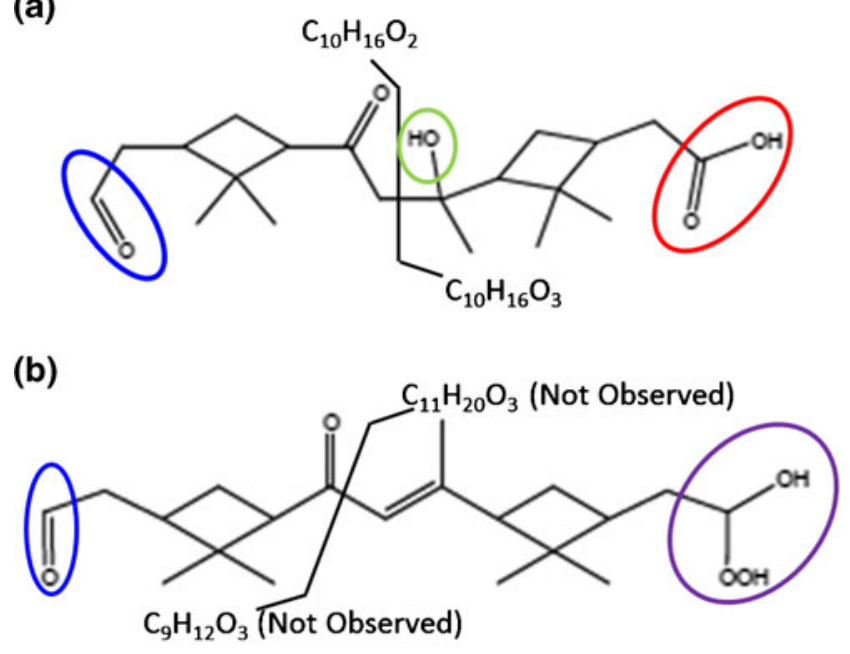

(c)

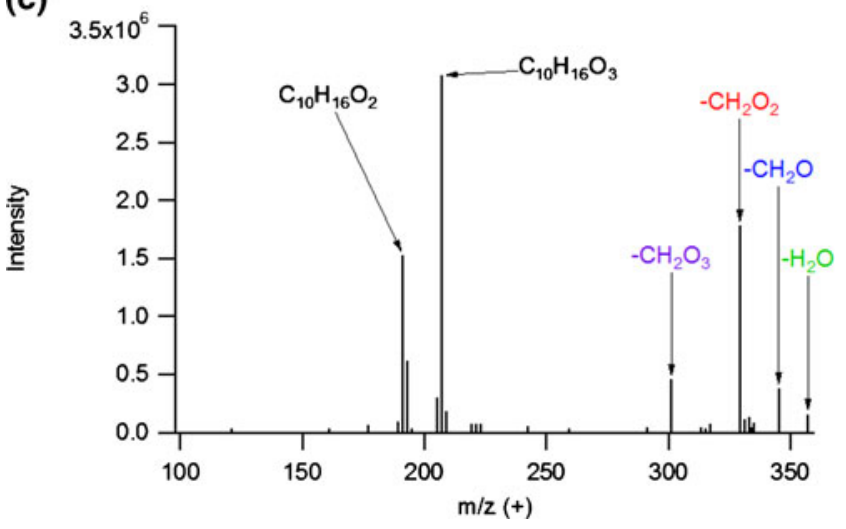

Figure 5. Evidence for an aldol reaction. (a) and (b) Structures of two compounds that match the elemental formula assigned to $m / z$ 375.214. (c) Fragmentation spectrum for isolation of $\mathrm{m} / \mathrm{z} 375$

provide evidence for di( $\alpha$-hydroxy) ether and peroxyhemiacetal formation.

\section{Secondary Ozonide Formation (m/z 405.188)}

Determining the presence of a secondary ozonide is less certain because it shares many fragmentation features with a peroxyhemiacetal. The strongest evidence is the precursor at $m / z$ 405.188, assigned formula $\mathrm{C}_{20} \mathrm{H}_{30} \mathrm{O}_{7} \mathrm{Na}^{+}$with a mass accuracy of $2.52 \mathrm{ppm}$ (Supplemental Figure S4). The two product series $\mathrm{C}_{10} \mathrm{H}_{14} \mathrm{O}_{3-5} \mathrm{Na}^{+}$and $\mathrm{C}_{10} \mathrm{H}_{16} \mathrm{O}_{2-4} \mathrm{Na}^{+}$in Figure $\mathrm{S} 4$ indicate a peroxide or secondary ozonides, which leaves two possible matches: a secondary ozonide formed from the reaction of SCI 1 and 10-oxopinonic acid (reaction 2D in Figure S3), and a peroxyhemiacetal formed from the reaction of 4-oxopinonaldehyde and hydroperoxide intermediate no. 2 (reaction 2E in Figure S3). As shown in Figure S4, both dimers are able to explain the major fragmentation peaks in the spectrum. However, the neutral losses of $\mathrm{H}_{2} \mathrm{O}, \mathrm{CH}_{2} \mathrm{O}_{2}$, and $\mathrm{C}_{2} \mathrm{H}_{2} \mathrm{O}_{2}$ are unlikely for 
(a)

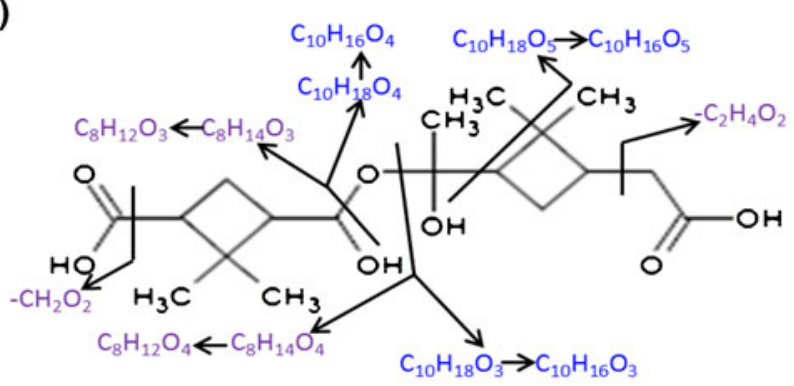

(b)

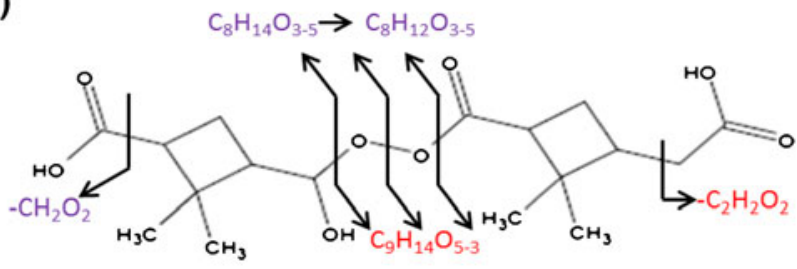

(c)

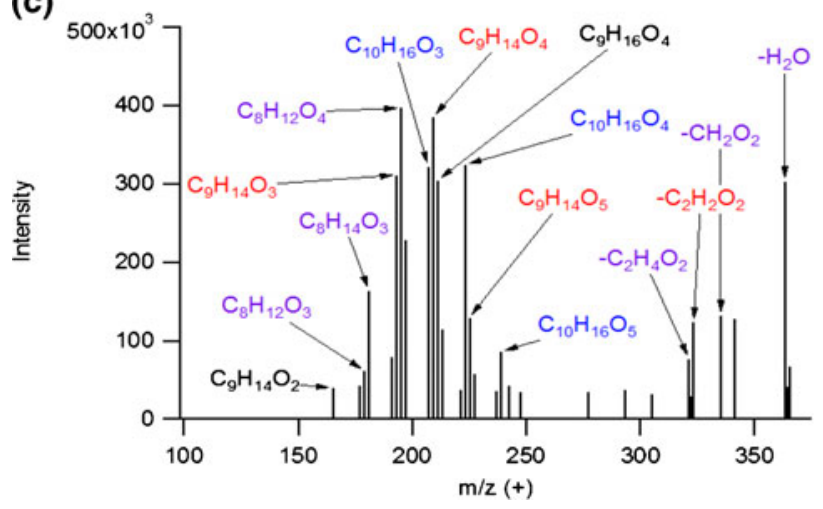

Figure 6. Evidence for di(a-hydroxy) ether and peroxyhemiacetal formation. Proposed dimer structures are shown for $\mathrm{m} / \mathrm{z} 381.188$ (a) the di(a-hydroxy) ether) and $\mathrm{m} / z 381.152$ (b) the peroxyhemiacetal). (c) Fragmentation spectrum for isolation of $\mathrm{m} / \mathrm{z}$ 381. Red indicates fragments from the di(ahydroxy) ether, blue fragments from the peroxyhemiacetal, purple fragments that could be attributed to either, and black for peaks that are not explained by either structure

peroxide, but are easily explained by the secondary ozonide structure.

\section{Other Reaction Types}

With the exception of an SCI-SCI reaction (reaction type 10, Table 1), precursors were found whose assigned formulas matched expected dimer products formed by all other reaction types considered: hemiacetal/hemiketal, ester, anhydride, alkylperoxide, and dehydrated di( $\alpha$-hydroxy) ether and aldols. In most cases, these spectra would also have peaks that corresponded to either one $(89 \%)$ or both $(69 \%)$ of the dimers reactants. Unfortunately, the spectral complexity and large number of possible dimer matches ruled out definitive assignments.

\section{Mechanism of Oligomer Formation}

Although the chemistry of $\alpha$-pinene ozonolysis is complex, accurate mass measurements of precursor and product ions can provide significant insight into monomer building blocks and oligomer formation routes when the assignments are constrained by known monomers and intermediates (Figures S1 and S2) and expected reactivity based on organic functional groups (Figure S3).

The lack of a relationship between the ability of a monomer to engage in oligomer formation (as indicated by the number of times the monomer is observed as an oligomer building block) and vapor pressure has several implications for the mechanism of SOA formation. First, it provides experimental confirmation of theoretical predictions for SOA formation from $\alpha$-pinene ozonolysis that relatively volatile organic compounds can contribute substantially to condensational growth of aerosol through oligomer formation [21]. As shown in Figure 2, compounds with a vapor pressure as high as $0.1 \mathrm{mmHg}$ can serve as preferred building blocks for oligomers in the particle phase even though the unreacted monomers contribute negligibly to SOA mass. Second, the lack of a vapor pressure dependence provides further confirmation that oligomer formation is fast [7]. Oligomer formation is unlikely to be driven by equilibrium partitioning of a monomer between the gas and particle phases with subsequent reaction to form an oligomer. Such a mechanism would proceed at a rate determined by the monomer particle phase concentration, which would necessarily imply a vapor pressure dependence. Instead, oligomer formation should be viewed as reactive uptake, where a gas phase monomer collides with the particle surface and becomes incorporated into the particle phase by rapid formation of a nonvolatile oligomer.

With respect to oligomer formation routes, accurate mass product ion spectra provide compelling evidence for specific reaction pathways. First, several examples are found of peroxyhemiacetal and/or acyl hydroperoxide oligomers formed by the reaction of hydroperoxide monomers. Peroxyhemiacetals in particular are significant because they have been reported as making up a large portion of SOA [26] and, indeed, are found in several of the oligomer mass spectra in this work. In the past, these products in SOA from $\alpha$-pinene ozonolysis were inferred using a combination of iodometric spectrophotometric titration with an examination of fragment ions formed by thermal desorption particle beam mass spectrometry [22], but direct molecular confirmation in oligomers has been lacking. Rapid formation of oligomers of this type is consistent with the high reactivity of hydroperoxide building blocks. Second, examples are found of oligomers formed by classic carbonyl chemistry, including aldol and gem-diol reactions [9,20]. Again, these reactions were postulated in previous studies of $\alpha$-pinene SOA, but compelling molecular evidence for them has been lacking. In the present study, the strongest evidence for these reactions is in the formation of hydrated products. Evidence for the 
dehydrated products is weaker. One may conjecture that formation of the hydrated products is fast, but dehydration is slower and may account in part for oligomer evolution over long periods of time [23]. Third, there is some evidence for secondary ozonide formation by reaction of the SCI with a monomer product of $\alpha$-pinene ozonolysis. These compounds are not expected to be significant contributors to SOA formed under ambient conditions because the SCI would be expected to react quickly with water. However, they have been postulated as nucleating agents for SOA produced under laboratory conditions $[24,25]$. Of all the reactions postulated for oligomer formation, the only one that can be eliminated (in other words, there is no evidence at all in the dataset to support formation of an appropriate product) is the self-reaction of the $\mathrm{SCI}$ as shown by reaction 5D in Figure S3. In previous work, reaction of the SCI to form an ROOR type molecule has been suggested by the presence of diagnostic fragment ions from SOA produced from cyclohexane [26] and products having nominal $\mathrm{m} / \mathrm{z}$ values that match probable ROOR products in SOA produced from isoprene [27].

Finally, it should be emphasized that definitive proof of the aforementioned products and reaction pathways would require synthesis and characterization of a wide range of monomers and oligomers relevant to the precursor and product ions. Such a task is daunting with respect to time, effort, and complexity. The current study, though, provides substantial evidence supporting the most important reaction pathways that have been postulated for oligomer formation. Going forward, the current study provides greater certainty that modeling SOA formation based on these reactions provides a reasonable representation of the chemical processes involved, at least under laboratory reaction conditions.

\section{Acknowledgements}

The authors acknowledge support for this research by the National Science Foundation under grant number CHE0808972 .

\section{References}

1. Hallquist, M., Wenger, J.C., Baltensperger, U., Rudich, Y., Simpson, D., Claeys, M., Dommen, J., Donahue, N.M., George, C., Goldstein, A. H., Hamilton, J.F., Herrmann, H., Hoffmann, T., Iinuma, Y., Jang, M., Jenkin, M.E., Jimenez, J.L., Kiendler-Scharr, A., Maenhaut, W., McFiggans, G., Mentel, T.F., Monod, A., Prevot, A.S.H., Seinfeld, J. H., Surratt, J.D., Szmigielski, R., Wildt, J.: The formation, properties, and impact of secondary organic aerosol: current and emerging issues. Atmos. Chem. Phys. 9, 5155-5236 (2009)

2. Kanakidou, M., Seinfeld, J.H., Pandis, S.N., Barnes, I., Dentener, F.J., Facchini, M.C., Van Dingenen, R., Ervens, B., Nenes, A., Nielsen, C.J., Swietlicki, E., Putaud, J.P., Balkanski, Y., Fuzzi, S., Horth, J., Moortgat, G.K., Winterhalter, R., Myhre, C.E.L., Tsigaridis, K., Vignati, E., Stephanou, E.G., Wilson, J.: Organic aerosol and global climate modelling: a review. Atmos. Chem. Phys. 5, 1053-1123 (2005)

3. Kroll, J.H., Seinfeld, J.H.: Chemistry of secondary organic aerosol: Formation and evolution of low-volatility organics in the atmosphere. Atmos. Environ. 42, 3593-3624 (2008)
4. Pankow, J.F.: Gas/particle partitioning of neutral and ionizing compounds to single and multi-phase aerosol particles. 1. Unified modeling framework. Atmos. Environ. 37, 3323-3333 (2003)

5. Gao, S., Keywood, M., Ng, N.L., Surratt, J., Varutbangkul, V., Bahreini, R., Flagan, R.C., Seinfeld, J.H.: Low-Molecular-Weight and Oligomeric Components in Secondary Organic Aerosol from the Ozonolysis of Cycloalkenes and $\alpha$-Pinene. J. Phys. Chem. A 108, 10147-10164 (2004)

6. Hall, W.A., Johnston, M.V.: Oligomer Content of $\alpha$-Pinene Secondary Organic Aerosol. Aeros. Sci. .Technol 45, 37-45 (2011)

7. Heaton, K.J., Dreyfus, M.A., Wang, S., Johnston, M.V.: Oligomers in the Early Stage of Biogenic Secondary Organic Aerosol Formation and Growth. Environ. Sci. Technol. 41, 6129-6136 (2007)

8. Heaton, K.J., Sleighter, R.L., Hatcher, P.G., Hall IV, W.A., Johnston, M.V.: Composition Domains in Monoterpene Secondary Organic Aerosol. Environ. Sci. Technol. 43, 7797-7802 (2009)

9. Tolocka, M.P., Jang, M., Ginter, J.M., Cox, F.J., Kamens, R.M., Johnston, M.V.: Formation of Oligomers in Secondary Organic Aerosol. Environ. Sci. Technol. 38, 1428-1434 (2004)

10. Nizkorodov, S.A., Laskin, J., Laskin, A.: Molecular chemistry of organic aerosols through the application of high resolution mass spectrometry. Phys. Chem. Chem. Phys. 13, 3612-3629 (2011)

11. Reinhardt, A., Emmenegger, C., Gerrits, B., Panse, C., Dommen, J., Baltensperger, U., Zenobi, R., Kalberer, M.: Ultrahigh mass resolution and accurate mass measurements as a tool To characterize oligomers in secondary organic aerosols. Anal. Chem. 79, 4074-4082 (2007)

12. Müller, L., Reinnig, M.-C., Hayen, H., Hoffmann, T.: Characterization of oligomeric compounds in secondary organic aerosol using liquid chromatography coupled to electrospray ionization Fourier transform ion cyclotron resonance mass spectrometry. Rap. Commun. Mass Spectrom. 23, 971-979 (2009)

13. Gao, Y., Hall, W.A., Johnston, M.V.: Molecular composition of monoterpene secondary organic aerosol at low mass loading. Environ. Sci. Technol. 44, 7897-7902 (2010)

14. Schmitt-Kopplin, P., Gelencsér, A., Dabek-Zlotorzynska, E., Kiss, G., Hertkorn, N., Harir, M., Hong, Y., Gebefügi, I.: Analysis of the unresolved organic fraction in atmospheric aerosols with ultrahighresolution mass spectrometry and nuclear magnetic resonance spectroscopy: organosulfates as photochemical smog constituents. Anal. Chem. 82, 8017-8026 (2010)

15. Guenther, A., Hewitt, C.N., Erickson, D., Fall, R., Geron, C., Graedel, T., Harley, P., Klinger, L., Lerdau, M., McKay, W.A., Pierce, T., Scholes, B., Steinbrecher, R., Tallamraju, R., Taylor, J., Zimmerman, P.: A global model of natural volatile organic compound emissions. $J$. Geophys. Res. 100, 8873-8892 (1995)

16. Claeys, M., Iinuma, Y., Szmigielski, R., Surratt, J.D., Blockhuys, F., Van Alsenoy, C., Böge, O., Sierau, B., Gómez-González, Y., Vermeylen, R., Van der Veken, P., Shahgholi, M., Chan, A.W.H., Herrmann, H., Seinfeld, J.H., Maenhaut, W.: Terpenylic acid and related compounds from the oxidation of $\alpha$-pinene: implications for new particle formation and growth above forests. Environ. Sci. Technol. 43, 6976-6982 (2009)

17. Yu, J., Cocker, D.R., Griffin, R.J., Flagan, R.C., Seinfeld, J.H.: Gasphase ozone oxidation of monoterpenes: gaseous and particulate products. J. Atmos. Chem. 34, 207-258 (1999)

18. Johnson, D., Marston, G.: The gas-phase ozonolysis of unsaturated volatile organic compounds in the troposphere. Chem. Soc. Rev. 37, 699-716 (2008)

19. Estimation Programs Interface Suite ${ }^{\mathrm{TM}}$ for Microsoft ${ }^{(\mathbb{R}}$ Windows, v 4.10, United States Environmental Protection Agency, Washington, DC, USA (2011)

20. Myoseon, J., Czoschke, N.M., Sangdon, L., Kamens, R.M.: Heterogeneous atmospheric aerosol production by acid-catalyzed particle-phase reactions. Science 298, 814-817 (2002)

21. Vesterinen, M., Lehtinen, K.E.J., Kulmala, M., Laaksonen, A.: Effect of particle phase oligomer formation on aerosol growth. Atmos. Environ. 41, 1768-1776 (2007)

22. Docherty, K.S., Wu, W., Lim, Y.B., Ziemann, P.J.: Contributions of organic peroxides to secondary aerosol formed from reactions of monoterpenes with $\mathrm{O}_{3}$. Environ. Sci. Technol. 39, 4049-4059 (2005)

23. Crehuet, R., Anglada, J.M., Bofill, J.M.: Tropospheric formation of hydroxymethyl hydroperoxide, formic acid, $\mathrm{H}_{2} \mathrm{O}_{2}$, and $\mathrm{OH}$ from carbonyl oxide in the presence of water vapor: a theoretical study of the reaction mechanism. Chemistry, Eur. J. 7, 2227-2235 (2001) 
24. Lee, S., Kamens, R.M.: Particle nucleation from the reaction of $\alpha$-pinene and $\mathrm{O}_{3}$. Atmos. Environ. 39, 6822-6832 (2005)

25. Tolocka, M.P., Heaton, K.J., Dreyfus, M.A., Wang, S., Zordan, C.A., Saul, T.D., Johnston, M.V.: Chemistry of particle inception and growth during $\alpha$ pinene ozonolysis. Environ. Sci. Technol. 40, 1843-1848 (2006)

26. Ziemann, P.J.: Evidence for low-volatility diacyl peroxides as a nucleating agent and major component of aerosol formed from reactions of $\mathrm{O}_{3}$ with cyclohexene and homologous compounds. J. Phys. Chem. A 106, 4390-4402 (2002)

27. Ng, N.L., Kwan, A.J., Surratt, J.D., Chan, A.W.H., Chhabra, P.S., Sorooshian, A., Pye, H.O.T., Crounse, J.D., Wennberg, P.O., Flagan, R. C., Seinfeld, J.H.: Secondary organic aerosol (SOA) formation from reaction of isoprene with nitrate radicals $\left(\mathrm{NO}_{3}\right)$. Atmos. Chem. Phys. 8, $4117-4140$ (2008) 